Contextual Factors Affecting Inclusion during Children's Transitions from Preschool to School

CHILDforum $8^{\text {th }}$ Annual NZ Early Childhood Research Symposium, 23 Nov 2004. Wellington College of Education, NZ:

Dr Christine Rietveld

Education Department

University of Canterbury

Christchurch 


\title{
Contextual Factors Affecting Inclusion during Children's Transitions from Preschool to School
}

\begin{abstract}
This qualitative study investigated the experiences of 2 pairs of boys ( 1 typically developing, 1 with Down Syndrome) during their transitions to school. The boys were observed using continuous narrative recordings during all aspects of the curriculum. Their teachers, parents and peers were also interviewed. Results indicated that the boys with Down Syndrome (DS) engaged in a narrower range of roles than the typically developing boys at preschool. Essentially, they were included in level 1 type inclusion (interactions that did not involve any emotional connections with specific children). However, observations at school indicated that inclusion or exclusion were not within-child characteristics, but largely dependent on the context. By the end of the first week of school, one child with DS was actively included in the full range of roles characteristic for that setting (levels 1 and 2 inclusion). Furthermore, one typically developing child who experienced both forms of inclusion at preschool was excluded at school. He experienced mostly interactions characteristic of level 1 type of inclusion at school. The data suggest that the nature of relationships in each context affected inclusion and exclusion more than the setting (preschool or school) or the presence of DS. These relationships were shaped by all levels of the centre or school's educational culture and beliefs, which permeated through the curriculum, pedagogy, assessment processes and ethos of the institutions, which in all but one school were based on an absence of disability as a prevailing norm.
\end{abstract}


Rietveld, C. (2004, November). Contextual Factors Affecting Inclusion during Children's Transitions from Preschool to School. CHILDforum $8^{\text {th }}$ Annual NZ Early Childhood Research Symposium, Wellington. Please cite author and reference if using this material.

The transition from preschool to school is an opportune time to investigate the process of inclusion in two different settings. As this marks entry into the formal education system, many aspects of the process are likely to become transparent as early childhood settings, families, schools and in some situations professionals share information and engage in actions to facilitate the child's adjustment and hence, inclusion. Few empirical studies have focused on how children with impairments experience the transition to school. Those available indicate that the stresses surrounding transitions for typically developing children (Peters, 1997; Renwick, 1984) tend to be compounded for children with impairments, their families and possibly schools (Bentley-Williams \& Butterfield, 1996; Wartmann, 1997) as schools and communities have evolved without the beliefs and expertise necessary for successfully including children from minority groups (Ballard, 1991; Kliewer, 1998).

The failure of regular preschools and schools to provide for children with diverse impairments until recent decades has been due to particular understandings, assumptions and values concerning disability, which underpinned their exclusion. Historically, the focus has been on biological limitations that were assumed to be static and all-encompassing characteristics, as opposed to one of many dynamic attributes that shift depending upon the context. The deficit view of disability located the issue within the individual (Oliver, 1996), thereby ignoring the role of social or external factors. In line with this view, the individual was considered to be a burden to families (Farber, 1960) regular educational settings (Clarke \& Clarke, 1974) and the community (Appendix to the Journals of the House of Representatives of New Zealand, 1956) and the response involved segregation for care and protection and 'treatment' for their deficiencies (Appendix to the Journals of the House of Representatives of New Zealand, 1956; Hunt, 2000). A prevalent discourse reflecting such deficit thinking is the personal tragedy or charity view of disability, (Oliver, 1996) which views people with impairments as "dependent, childlike, helpless, passive, needy and requiring compensation" (Neilson, 2002, p. 21). In educational settings, this can result in educators and peers responding to children with impairments in compensatory rather than educational ways, thus limiting their opportunities for learning (Philips, 1997; Rietveld, 2004). 
Rietveld, C. (2004, November). Contextual Factors Affecting Inclusion during Children's Transitions from Preschool to School. CHILDforum $8^{\text {th }}$ Annual NZ Early Childhood Research Symposium, Wellington. Please cite author and reference if using this material.

More recently, the historical deficit discourse of disability has been challenged as disability activists and theorists and parents claim that it is not individual characteristics that disable, but contexts that fail to cater adequately for people with impairments (Clough \& Barton, 1995; Oliver, 1986, 1996). This locates the issue of disability externally as specified in the NZ Disability Strategy, "Disability is the process which happens when one group of people create barriers by designing a world only for their way of living, taking no account of the impairments other people have" (Minister for Disability Issues, 2001, p. 3). While not ignoring the existence of impairments and/or the usefulness of medical and therapeutic treatments (Barnes, 2003), the social model of disability acknowledges that how impairments are classified, treated and interpreted is socially constructed. The focus then shifts from the (deficit) individual to how mainstream contexts such as early childhood centres and schools respond to diversity.

Processes such as inclusion and transition to school can best be understood within a transactional model of development since the child's characteristics and her/his immediate and wider social systems interact constantly with one another. Brofenbrenner's ecological model (1979) and Vygotsky's theory of learning (1981) share elements in common with the social model of disability. A common feature is their focus on the child's functioning within her/his immediate contexts and their consideration of the broader social, political and structural factors impacting on that functioning. These models are therefore helpful in understanding whether the processes occurring during inclusion and transition are facilitative and supportive of development. Inherent in a successful transition is becoming a valued, included member of the classroom and its subgroups. It is within such groups that culturally valued learnings necessary for living in an inclusive society take place (Vygotsky, 1978). This necessarily involves being treated as an equal, valued and contributing member of the centre, class and school and participation in the full range of culturally-valued roles of that setting (MacArthur, Purdue \& Ballard, 2003; Rietveld, 2002). When learning is conceptualised as a function of the quality of interactions with more skilled learners, it becomes evident that i) the quality of the child's interactions and relationships with more expert learners is essential for optimal learning outcomes and ii) given the broader goal of an inclusive society, of which inclusive preschools and schools are components (NZ Disability Strategy, 2001), 
Rietveld, C. (2004, November). Contextual Factors Affecting Inclusion during Children's Transitions from Preschool to School. CHILDforum $8^{\text {th }}$ Annual NZ Early Childhood Research Symposium, Wellington. Please cite author and reference if using this material.

classmates need to be included into processes involving the valuing of diversity and the establishment of an inclusive learning community. Children cannot learn to include by avoiding contact or they cannot learn to include more effectively if they relate to children with impairments in stereotypical ways and the wider context fails to provide the necessary learning/scaffolding for the development of more mutuallyenhancing interactions (Biklen, 1985). The transition to school provides the context for the interplay of the child's immediate and more distal systems. In a successful transition, the child, classmates and teacher are engaged in interactions that lead to culturally appropriate and valued outcomes. For such educational outcomes to accrue in the child's microsystem, they need to be accompanied by similar congruent processes involving trust and goal-consensus throughout the infrastructure of other systems affecting, but not containing the child.

Few, if any studies of children with impairments have investigated whether the outcomes following their transitions to school have been successful for the children, their families, schools and communities in terms of the quality of the children's experiences (their inclusion into enabling processes and outcomes). Previous studies have investigated isolated aspects of the transition process, such as the parents' (usually mothers') perspectives (Bentley-Williams \& Butterfield, 1996; HamblinWilson \& Thurman, 1990), recommended practices (e.g. the importance of shared processes, adequate funding) without identifying the goal of those processes which is presumably facilitative inclusion (Wartmann; 1997) or used global measures of success, such as a child not having to repeat a grade (Conn-Powers, Ross-Allen \& Holburn, 1990) or a schools and parents' commitment to the process (Ward \& Center, 1988). Since such studies provide no or minimal data on whether the children's experiences were facilitative of development, it is unknown whether the children's experiences were enabling and actually reflected the philosophy underlying inclusion as specified in the NZ Disability Strategy (2001). These include: providing "the best education for disabled people" (p. 11) and "encourage and educate for a non-disabling society" (p. 11).

These shortcomings in the literature prompted this study with its focus on DS to determine what happens during children's transitions from preschool to primary school. More specifically, the research questions were: 
Rietveld, C. (2004, November). Contextual Factors Affecting Inclusion during Children's Transitions from Preschool to School. CHILDforum $8^{\text {th }}$ Annual NZ Early Childhood Research Symposium, Wellington. Please cite author and reference if using this material.

1) What are the experiences of children with DS in the inclusive or exclusive contexts of their respective preschools and schools and how do these experiences compare with those of typically developing children?

2) What accounts for the children's differing experiences of inclusion/exclusion in both their immediate and more distal systems?

\section{METHOD}

Participants and Settings: Two boys with DS (Ian and Jonathan) and two typically developing boys (Jacob and Neil), their parents, teachers and other key people involved with their transition to school participated in this study. All the children were 4 years 11 months at the beginning of the study. Ian and Jacob attended the same local early childhood centre and school, while Jonathan and Neil attended different local early childhood settings ${ }^{1}$ but the same school. The schools were in middle-high socio-economic suburbs of a large city. All boys came from supportive 2-parent families. The boys with DS and their families had taken part in a quality early intervention programme (Champion, 1987) since birth, which provided the families with support, knowledge and skills in providing optimal learning environments for their children.

\section{Data Sources and Analysis}

- Running record observations were undertaken during their final week of preschool (8 hours), during the first 6 weeks of school (37-39 hours) and 3-4 months after school entry (5-6 hours)

- Interviews with parents and educators were undertaken throughout

- Other: field notes, permanent products, meeting observations

Data gathering was influenced by Bronfenbrenner's (1979) bio-ecological model based on the premise that the child is at the centre of and is affected by and affects several environmental systems, ranging from immediate settings such as the family, preschool or classroom to more remote contexts such as the quality of home-school relations,

\footnotetext{
1 There was no boy from Jonathan's early childhood centre due to start at his primary school that particular term, which is why Neil from a neighbouring centre was selected.
} 
Rietveld, C. (2004, November). Contextual Factors Affecting Inclusion during Children's Transitions from Preschool to School. CHILDforum $8^{\text {th }}$ Annual NZ Early Childhood Research Symposium, Wellington. Please cite author and reference if using this material.

level of professional and practical support which are also influenced by broader cultural values and policies.

The data were analysed inductively for themes and patterns, describing the kinds of inclusion/exclusion and underlying processes taking place. Comparisons were made between children with and without DS and among the different institutions

\section{RESULTS AND DISCUSSION}

After reviewing the data for all the children with and without DS in both preschool and school settings, the full range of peer interactions reflected these categories

\section{$\underline{1 . \text { Exclusion (3 types) }}$}

a) Active exclusion, b) Passive exclusion, c) Teasing

\section{Ineffective or Illusory inclusion}

a) Assigning child inferior roles, such as baby, pet, subordinate or object, oddity

b) Including child to take risks for own purposes (e.g. to steal)

c) Participation in equal status interactions, but only in a narrow range of roles where connections between participants is superficial (e.g. politeness, occasional playmate). Might include lengthy episodes of interactive play but the participants do not seek one another out again. (Level 1 inclusion)

\section{Facilitative/Authentic Inclusion (Level 2 inclusion)}

a) Participation in: equal status, reciprocal relationships (i.e. category c above) and

b) the full range of roles pertinent for that setting (from politeness to friendships)

Level 2 inclusion involves being included as a valued member of the class on a consistent basis by at least some members. i.e. belonging/having emotional connections with a specific friend(s) or groups(s) as well as participation in Level 1 inclusion. Experiencing this form of inclusion reflects the philosophy underlying the NZ Disability Strategy (2001) and is facilitative of development and learning.

Participation in Level 2 inclusion at school was associated with 
Rietveld, C. (2004, November). Contextual Factors Affecting Inclusion during Children's Transitions from Preschool to School. CHILDforum $8^{\text {th }}$ Annual NZ Early Childhood Research Symposium, Wellington. Please cite author and reference if using this material.

a) Meaningful gains in terms of culturally-valued skills, e.g. enhanced literacy skills

b) Classmates responding to diversity respectfully and becoming more skilful over time

Experiencing Level 1 as well as Level 2 inclusion is considered facilitative as being included in ongoing less-intimate roles e.g. exchanging pleasantries, working with an assigned partner is an essential part of belonging to the wider (classroom) community even if one has specific connections with a particular peer or group(s). Another reason why Level 1 type inclusion is important is because when friendships dissolve, the child has a supportive pool of others with whom she/he can develop new friendships. Finally, in an inclusive society all children need to learn how to relate respectfully to and appropriately with children with impairments and they cannot do so, if they are never within a zone of proximal development. i.e. they avoid contact with the child or the child is unavailable. At the same time, it is problematic when children only experience less intimate forms of inclusion because the more intimate forms permit greater opportunities and learnings conducive to a quality life-style, which is denied to those experiencing illusory inclusion or exclusion (HarlanSimmons, Holtz, Todd \& Mooney, 2001). 
Rietveld, C. (2004, November). Contextual Factors Affecting Inclusion during Children's Transitions from Preschool to School. CHILDforum $8^{\text {th }}$ Annual NZ Early Childhood Research Symposium, Wellington. Please cite author and reference if using this material.

\section{How did the participants experience inclusion?}

The experiences of the 4 participants are shown in Figure 1.

Figure 1: Participants' experiences of facilitative/authentic inclusion or exclusion in each setting

\section{Early Childhood Centre $\quad$ School}

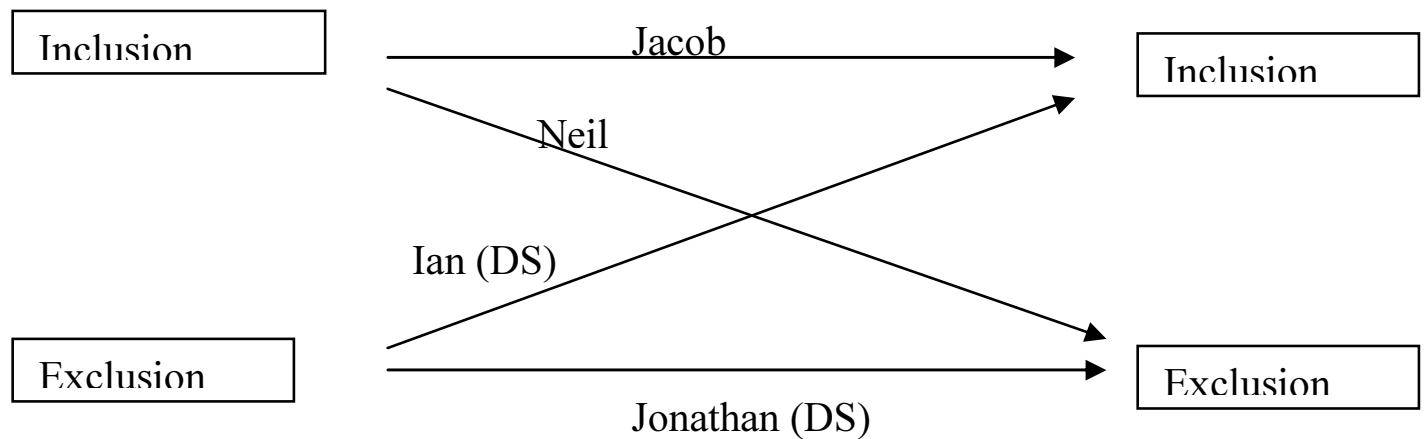

As can be seen, none of the boys with DS (Ian or Jonathan) experienced authentic/facilitative inclusion (interactions comprising both Levels 1 and 2 forms of inclusion) at preschool while both typically developing boys (Jacob and Neil) did. However, irrespective of impairment, these outcomes and underlying processes changed at primary school for two of the children (Ian and Neil). These changes occurred in different directions. While Ian became an included member at school towards the end of his first week, Neil who was included at preschool was excluded for his first six weeks prior to the summer holidays. Facilitative inclusion only occurred after changes in class composition. Jonathan experienced exclusion in both settings, while Jacob was the only child to experience inclusion in both settings.

The differences in the experiences of children with and without DS at preschool were not evident at school where there was more variation between the schools than between the children with and without DS. If the characteristics of DS inevitably led to exclusion and the absence of DS resulted in inclusion, then one would expect all the boys with DS to be excluded and the typically developing boys included regardless of settings. Furthermore, the finding that there were major changes in Ian and Neil's experiences of inclusion/exclusion after their transitions to school, 
Rietveld, C. (2004, November). Contextual Factors Affecting Inclusion during Children's Transitions from Preschool to School. CHILDforum $8^{\text {th }}$ Annual NZ Early Childhood Research Symposium, Wellington. Please cite author and reference if using this material.

provides further support for the significant role contexts play in facilitating inclusion or exclusion. Given that Neil (a competent typically developing child who was wellliked at preschool) could not gain access to more advanced forms of inclusion, despite considerable efforts on his part involving a range of mature strategies and that Ian who engaged consistently in anti-social behaviour at preschool, but began to use more socially appropriate behaviours within his first week of school strongly suggested that inclusion and exclusion were not disability, but curriculum and management issues.

\section{Case Study: Ian (DS)}

An example of one child's experiences before and after his transition to school (i.e. during the last week at his early childhood centre where he experienced illusory inclusion and then at school when he experienced facilitative/authentic inclusion) follows. This case study was selected because it illustrates clearly the socially constructed nature of disability and its impact on outcomes before and after the transition to school. Direct and indirect practices impacting on these interactions follow.

\section{Illusory Inclusion (Early Childhood Centre)}

Context: Book corner - 3-4 children including Ian waiting for their parents to collect them

Ian and William are looking at the same book. Ian labels all the zoo animals correctly. William ignores Ian's vocalisations and makes up a story about the animals. Incorrectly labels the camel a kangaroo. Ian points out and says, "Monkey. Another child looks on. William says to the child, 'I'm not reading you a story. I'm reading Ian a story." William's mother arrives. William hands the book to Ian and says to his mother, "I'm reading Ian a story." His mother asks, "Are you?" William and his mother depart. [Observer comment: No farewell greeting to Ian] After a similar incident on another day, the teacher rewards the typically developing child for reading to Ian, "That was very kind of you."

\section{$\underline{\text { Interpretation of Inclusion }}$}

The peer (William) takes on the dominant role ("I'm reading Ian a story") and sees himself engaging in a generous act as opposed to a mutually shared activity. Ongoing 
Rietveld, C. (2004, November). Contextual Factors Affecting Inclusion during Children's Transitions from Preschool to School. CHILDforum $8^{\text {th }}$ Annual NZ Early Childhood Research Symposium, Wellington. Please cite author and reference if using this material.

interactions of this nature where the minority status child is ignored are likely to compromise developmental processes such as self-agency, self-worth, language and social relationships.

Ian is constructed as an object that can be 'discarded' when time for the favour is over. There was no personal connection - no farewell greeting on departure, which was uncommon amongst the contrast children in similar contexts.

There was no reciprocity or shared meanings - essential for more advanced forms of inclusion for both participants. Ian's contributions are ignored, including his correct labelling of the kangaroo. Ignoring his contribution suggests the low status this peer assigns Ian. Ongoing interactions of this nature place Ian at-risk for internalising such beliefs about himself and his abilities.

\section{Teacher Behaviour}

All staff engaged in practices stemming from the deficit/personal tragedy model of disability. e.g. The children were rewarded for treating Ian as an object of charity "That was very kind of you" (reading a book to Ian).

The teachers never expected reciprocity from Ian, which reinforced his peers for viewing him as an object of charity. e.g. The teacher asks James to push Ian in a trolley which he does. After a substantial ride, Ian remains seated. The teacher says, "Thank you James. That was very kind of you (pushing Ian in trolley). Will you take him (Ian) round again?" There was no suggestion that Ian might give James a turn. Mutually-satisfying relationships require some forms of reciprocity. In the early childhood setting Ian did not appear to be provided with opportunities for learning this.

Ian engaged regularly in a number of anti-social behaviour (not evident in book corner scenario presented at the beginning of this case study). In order to help peers cope in these situations, the staff encouraged peers to verbally instruct Ian to terminate the undesired behaviour. However, no monitoring of this strategy appeared to take place and observations indicated it to be ineffective. This left Ian's peers powerless and contributed to at least some avoiding him. As one child stated, "But 
Rietveld, C. (2004, November). Contextual Factors Affecting Inclusion during Children's Transitions from Preschool to School. CHILDforum $8^{\text {th }}$ Annual NZ Early Childhood Research Symposium, Wellington. Please cite author and reference if using this material.

one day he throwed water over me. He's not a very nice boy." Another undesirable effect was that it cast Ian's peers into the role of mini-disciplinarians or teachers, thus promoting unequal relationships not conducive to authentic inclusion. While the children's response as disciplinarians may be interpreted as responsible, assertive behaviour, in absence of being presented with other forms of interaction, they were being excluded from more advanced forms of inclusion.

Children learnt to position Ian as 'other' (not like us) by the staff continuing conversations, which were meant for Ian but occurred as if he were not fully human or an integral member. For instance,

Kyle - Teacher, "Why has Ian got those trousers?" Why has he got bats on it?"

Teacher - Kyle, "Because he likes them."

Kyle - Teacher, "I love those batman pants."

Teacher - Ian, "Kyle likes your batman pants."

Such interactions constrained learning opportunities for how peers might interact with Ian directly.

The teachers also used Ian's peers as consultants about his behaviour, thus positioning them alongside the staff in a superior position to Ian. For instance, when Ian and several others were sitting in the book corner waiting for their parents to collect them, the teacher noticed a book on the floor and Ian not reading. She asked the group, "Did he (Ian) take a book and throw it?"

\section{Infra-structure supporting those Practices}

The staff resisted the alternative social construction model of disability and accompanying practices when suggested by the early intervention team. The head teacher had done a recent course on special needs, which involved practices indicative of the individualised personal tragedy deficit model, which she believed was the appropriate theoretical model to work from.

The preschool-parent-early intervention relationship was co-operative, warm and friendly, but critical information concerning Ian's anti-social behaviour was often withheld from the parents and early intervention team as one of the teachers reports, "We didn't tell her (Ian's mother) that he didn't have a good day. As a parent you can 
Rietveld, C. (2004, November). Contextual Factors Affecting Inclusion during Children's Transitions from Preschool to School. CHILDforum $8^{\text {th }}$ Annual NZ Early Childhood Research Symposium, Wellington. Please cite author and reference if using this material.

only hear so much of that and Susan (mother) was getting stressed, so we didn't tell her." This decision seemed to affect the quality of inclusion provided at the early childhood centre.

The Education Review Office report commended the early childhood centre for the way it included children with impairments, which provided reinforcement for existing practices.

\section{$\underline{\text { Illusory inclusion/exclusion (Pre-entry visit to School) }}$}

During Ian's pre-entry visit to school, it was clear that the children did not automatically know how to include Ian in the new setting.

Family corner (developmental time): Ian approaches the family corner. Kelly - Erin, "Oh no! Ian wants to play. Kelly asks the early intervention teacher, "Can you take Ian away?"

Blocks: Ian knocks over an upright block (possibly accidentally the first time, then later - deliberate?). Philip - Alex, "He's (Ian) spoiling the game" (3X). Philip to Ian, "You're naughty. I'll tell the teacher. I'll tell the teacher"... Philip to Alex, "He's not allowed on our road."

\section{Interpretation of Inclusion:}

Active exclusion (family corner) takes place. Ian is talked about as if he were an object.

Use of pronoun 'He' (blocks incident) indicates Philip sees Ian as 'other' (not part of us). Authentic inclusion calls for use of 'we'.

Peers do not display skills reflective of inclusion. They ask for Ian's removal (as if he is an object) and call in the teacher instead of dealing with the issue themselves.

\section{Authentic/Facilitative Inclusion (School)}

By the second week of school, Ian experienced inclusion as an equal same-status participant and he engaged in the full range of roles typical for that setting. As is 
Rietveld, C. (2004, November). Contextual Factors Affecting Inclusion during Children's Transitions from Preschool to School. CHILDforum $8^{\text {th }}$ Annual NZ Early Childhood Research Symposium, Wellington. Please cite author and reference if using this material.

evident from the data, the nature of the peer interactions, teacher practices and indirect practices differed markedly from those at the early childhood centre and his school pre-entry visits.

Example of Inclusion (Towards end of Term)

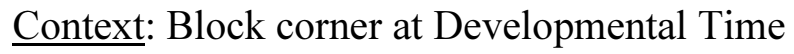

Each of the 4 children present including Ian have made their own houses. Ian puts a car in Alex' house. Alex to Ian, "No. Not in my house - in your (emphasised) house." Ian takes the car out and puts it in his own house and says to Alex, "In there. See." Alex to Ian, "Yes. You need to make a roof...like this...like this Ian." He shows Ian. Ian adds blocks in the same way Alex is showing him. Alex - Ian, "See the roof, Ian." Ian repeats, "Roof." Alex - Ian, "The house is all complete. It's a good house." Ian - Alex, "Thank you." Ian adds some blocks to the house....Alex to Ian, "We need to make a new road now." Ian repeats, "Road."

Interpretation of Inclusion

Ian is included as a valued participant

Reciprocity is evident between the participants. Ian is now a contributing member and shared meanings are evident. E.g. Ian shows Alex that he has moved the car to his own house.

Peer (Alex) deals with unconventional behaviour (Ian putting a car in his house without asking) - a potential site for exclusion. Alex explains and shows Ian in a respectful way.

Alex reinforces Ian's contribution, provides Ian with access to more advanced forms of understanding (how to build a roof) and involves him in a new aspect of the activity (joint creation of a road)

Alex emphasis critical words, something modelled by the teachers in view of children with DS having potential difficulties focusing on salient aspects.

Use of pronoun 'we' indicates Ian is now an integral member. 
Rietveld, C. (2004, November). Contextual Factors Affecting Inclusion during Children's Transitions from Preschool to School. CHILDforum $8^{\text {th }}$ Annual NZ Early Childhood Research Symposium, Wellington. Please cite author and reference if using this material.

\section{What has contributed to the shift in experiences?}

The first major change is the shift in philosophy of disability, which permeated all systems affecting the child. Instead of focussing on the child's deficits, the teacher, principal and all pertinent others focused on creating a context that was inclusive of all the children in the class. This was the only educational setting where the staff demonstrated an awareness of the two different perspectives underlying disability, inclusion and difference and demonstrated the ability to translate the philosophy into practice on a consistent basis.

\section{Teacher Practices}

The classroom norms already catered for diversity. The teacher and teacher-aide used Ian's enrolment to refine and expand the existing norms in a way that strengthened and altered the mainstream culture so that it became increasingly more responsive to diversity.

The teacher and teacher-aide recognised and interrupted demeaning or illusory inclusion e.g. excessive hugging, picking up.

The staff scaffolded children to re-frame any problems interpreted within the deficit framework to one that focussed on the context. They helped children develop strategies whereby Ian could be included. E.g. when Ian's peers complained to the teacher about him putting too many cars on a co-operatively-built block structure, which subsequently broke, she said, "If there's a problem, tell Ian what it is. Tell Ian if there's too many cars, it'll break. Tell him where he can put the cars and blocks".

The teacher also openly interpreted the likely intent of any unconventional behaviour (a potential site for exclusion) in a positive and valuing manner. E.g. When Ian moved some little chairs from the desks over to his mother and little sister during a pre-entry visit when the class were involved in a mat activity and a child called out to the teacher, "Look what Ian's doing", she responded calmly and positively by interpreting the likely intent of Ian's behaviour, "Yes, Ian's Mum can now sit on a chair". 
Rietveld, C. (2004, November). Contextual Factors Affecting Inclusion during Children's Transitions from Preschool to School. CHILDforum $8^{\text {th }}$ Annual NZ Early Childhood Research Symposium, Wellington. Please cite author and reference if using this material.

The teacher and teacher-aide included activities that highlighted Ian's competencies and interests in a way that made the overall class culture more inclusive for a greater range of children. E.g. the introduction and initial structuring of ball activities and games during interval-break and lunchtimes provided additional opportunities for other new entrants to experience inclusion.

The staff also facilitated Ian's inclusion within peer group norms, which at times differed from adult and classroom norms. E.g. Even though the children were expected to remain seated during their eating of lunch, Ian and his peer group made brief attempts at breaking this rule. When Ian's teacher noticed them engaging in a brief ritual which involved stamping their feet, standing up briefly and laughing after the duty teacher had walked by and was not looking, she smiled and commented to Ian's peer group, “Are you boys having fun?” thus supporting peer group norms and Ian's inclusion within those norms.

The teacher and teacher-aide consistently specified and reinforced social norms over procedural norms. E.g. waiting for Ian who was slower at walking back to class or for the new boy who was not sure where to go when the bell rang were more important considerations than being first in line.

Unlike at preschool, the classroom teacher always focused on the establishment of shared meanings and relationships in which there was a balance of power as opposed to rewarding one child (the one with majority status) for interacting with other. E.g. on observing Ian and a classmate jointly making dough cakes, the teacher responded, "It's nice seeing you play together. What beautiful cakes you 2 have made! Are they cooked?"

As part of valuing the whole child, the teacher and teacher-aide attempted to understand the implications of DS for learning and changed practices and norms to enable all the children's learning to be successful. For instance, researchers have found that children with DS have a number of neurological differences which are likely to reduce the accuracy, speed and consistency of motor responses that indirectly affect the precision, sequencing, timing and production of speech movements (Miller, Leddy, Molo, \& Sedey, 1995). To enable Ian to actively participate and benefit from 
Rietveld, C. (2004, November). Contextual Factors Affecting Inclusion during Children's Transitions from Preschool to School. CHILDforum $8^{\text {th }}$ Annual NZ Early Childhood Research Symposium, Wellington. Please cite author and reference if using this material.

his inclusion in a reading group, the teacher and/or teacher-aide slowed down the pace of the entire group's oral reading and at the same time specified other individualised goals for other children (e.g. reading with expression).

\section{Comparisons with Jonathan (DS) and Neil (Typically Developing)}

Jonathan's early childhood experiences were similar to Ian in that he experienced interactions characteristic of Level 1 inclusion (those where connections between participants were superficial) and exclusion. However, unlike Ian who experienced a richer and more inclusive learning context at school, Jonathan's schooling resulted in increasingly hostile forms of exclusion, illusory inclusion and Level 1 inclusion. At school, classmates interpreted Jonathan's differences as deviancy to which they responded by excluding him. School staff who either did not notice the exclusion or when they did, ignored it are likely to have contributed to the children's exclusion as the latter were not given access to a process to facilitate their classmates' inclusion. Since the school's definition of inclusion involved the assimilation of children with impairments into the school's existing culture, as opposed to changing the mainstream to accommodate the school's diversity, the practices instigated (e.g. working exclusively with the teacher-aide) are likely to have exacerbated Jonathan's exclusion as they were disconnected from the school and classroom's existing culture. Classing some students as 'deviant' or 'other' creates divisions of 'them' and 'us,' which is then used to justify the exclusion of some students from the curriculum. In contrast to Ian's school where the teacher supported children in reframing any problems they interpreted from a deficit perspective to one that focused on their providing an inclusive context, children in Jonathan's school learnt that it was acceptable to exclude when 'deviant' children did not fit the existing norms. For instance:

On Jonathan's fifth day, peers excluded Jonathan from the group's readingrelated activities by blocking access to the materials and activities, taking books from him and discussing what they saw as his incompetencies. When the teacher noticed Jonathan disrupting the matching word card activity, she used his 'inappropriate'/deviant behaviour as the reason for legitimising his segregation, "I think at this time he's quite disruptive. He might be better off one-to-one with a teacher-aide."

In the scenario, the children's exclusion of Jonathan is not interrupted nor is there any altering of the context to enable the group to work more inclusively. Instead the focus 
Rietveld, C. (2004, November). Contextual Factors Affecting Inclusion during Children's Transitions from Preschool to School. CHILDforum $8^{\text {th }}$ Annual NZ Early Childhood Research Symposium, Wellington. Please cite author and reference if using this material.

is on Jonathan's 'deficit' behaviour, irrespective of the context and nature of his impairment and the potential solution is his exclusion. In turn, the teacher's behaviour may be providing tacit support for the children's exclusionary behaviour.

In this school, the wider school culture was assumed to be facilitative of all other children's learning, which indeed it was not as at least two other minority status children were observed experiencing similar incidents of exclusion as was Neil, the typically developing child in this study. No attention to peer relationships, a lack of appropriate social norms (e.g. looking out for one another, ensuring no-one is left out), poor playground supervision, a focus on a narrow set of academic outcomes and a recitation task-structure (Bossert, 1979) made it difficult for any newcomer to become included as valued members of this class as evidenced through Neil's exclusion.

\section{Broader Infra-structure affecting Inclusion/Exclusion}

The quality of children's inclusion is not only affected by what occurs in the child's microsystem but also by wider systems impacting on that system. The following table illustrates some critical features, which differed between the settings in which they experienced facilitative/authentic inclusion from those where they experienced illusory inclusion or exclusion.

Table 1: Factors at Mesosystem and Exosystem levels (more distal levels) Conducive to Successful and Unsuccessful Inclusion in the Classroom

\begin{tabular}{|c|c|c|c|}
\hline & Issue & Successful Outcomes & Unsuccessful Outcomes \\
\hline 1 & Existing infra-structure & Accommodating of differences & Not accommodating \\
\hline 2 & $\begin{array}{l}\text { Vision of successful } \\
\text { outcomes by all }\end{array}$ & Yes & No \\
\hline 3 & $\begin{array}{l}\text { Knowledge to achieve } \\
\text { outcome }\end{array}$ & Yes & No \\
\hline 4 & Model of disability & Social construction & Individual deficit/mixed \\
\hline 5 & Principal & $\begin{array}{l}\text { Supports all in implementing } \\
\text { shared philosophy }\end{array}$ & $\begin{array}{l}\text { Supports mostly teacher: } \\
\text { focus on external resources }\end{array}$ \\
\hline
\end{tabular}


Rietveld, C. (2004, November). Contextual Factors Affecting Inclusion during Children's Transitions from Preschool to School. CHILDforum $8^{\text {th }}$ Annual NZ Early Childhood Research Symposium, Wellington. Please cite author and reference if using this material.

\begin{tabular}{|c|l|l|l|}
\hline 6 & Professionals & Inclusive philosophy required & Any philosophy \\
\hline 7 & Parents & $\begin{array}{l}\text { Authentic partnership with } \\
\text { sound knowledge base }\end{array}$ & $\begin{array}{l}\text { Devalued or authentic but } \\
\text { limited knowledge base }\end{array}$ \\
\hline 8 & Meetings & Focus: parent's concerns & $\begin{array}{l}\text { Parent's concerns dismissed } \\
\text { or goodwill, but no } \\
\text { knowledge of processes }\end{array}$ \\
\hline 9 & Historical approach & None & On-site special units \\
\hline 10 & Teacher-aide selection & $\begin{array}{l}\text { Trained teacher with inclusive } \\
\text { philosophy }\end{array}$ & $\begin{array}{l}\text { Special education } \\
\text { background }\end{array}$ \\
\hline 11 & Teacher-aide role & Team teaching & Attached to child \\
\hline 12 & Teacher support & $\begin{array}{l}\text { Parents and school staff with } \\
\text { shared vision }\end{array}$ & $\begin{array}{l}\text { Friendly relationships, but } \\
\text { lack of knowledge or conflict }\end{array}$ \\
\hline
\end{tabular}

Overall for children to experience facilitative inclusion and for a supportive infrastructure to maintain those outcomes, the most critical ingredients were:

1) An educational setting with a holistic approach to children's well-being and development, sensitive to the diversity in its existing population and engaging in practices, which characterise effective teaching.

2) A discourse of disability, which focuses on the context and sees disability as part of, not distinct from that context.

3) A vision of what successful inclusion might look like based on the social model, whilst acknowledging the nature of the impairment on the teaching-learning process, adherence to the model at all levels and ongoing monitoring by all key participants.

Historical connections with special education facilities, individuals or courses acted as an impediment to all of the above. The presence or absence of the above determined the direction of all other practices. At all levels, where outcomes were successful, these practices were used to strengthen the existing culture by broadening norms and therefore enabling a greater range of children to experience success. For instance, Ian's principal advocated for a trained teacher to team-teach, which meant more adult support was available for the class and the support and enjoyment the teachers derived from this arrangement enhanced their motivation to improve their inclusive teaching. Where outcomes were unsuccessful, all practices focused on the individual's 
Rietveld, C. (2004, November). Contextual Factors Affecting Inclusion during Children's Transitions from Preschool to School. CHILDforum $8^{\text {th }}$ Annual NZ Early Childhood Research Symposium, Wellington. Please cite author and reference if using this material.

deviancy, distinct from the existing classroom and preschool/school culture with no implementation or expansion of norms to embrace the kinds of diversity evident in the student population irrespective of the child with DS.

\section{SUMMARY/CONCLUSIONS}

This study has highlighted what inclusion involves at the 'chalk face' and identified some of the processes necessary to achieve it. Contexts clearly affect the quality of educational processes and outcomes, as evidenced by the children's differing experiences of inclusion and exclusion as they moved from one educational setting to another. Studying the same children in two settings as they moved from their early childhood centres to school indicate that inclusion is not a within-child characteristic, but dependent on the context. This highlights the importance of the transition process as clearly it provides a context in which new opportunities can be created. The challenge for educators, parents and professionals is to is recognise and facilitate the necessary processes at all levels of the school's educational culture and belief systems in order for favourable outcomes to accrue. At the same time, children, particularly those with impairments who are less likely to be able to compensate for poor opportunities (Brown, 1994) should not need to wait for transitions to new settings or classes to experience facilitative inclusion. It is of some concern that the quality of 'inclusion' experienced in the early childhood settings was less than optimal for the children with DS in that the parents and early intervention staff needed to facilitate major transformations in order for these boys to experience facilitative inclusion at school. Even then, the staff at Jonathan's school and the professional support they utilised were resistant to the philosophy and practices suggested, (although this was not obvious initially), so no meaningful outcomes could be actualised. One wonders what competencies Ian and Jonathan might have attained and how their (expreschool) peers might have facilitated their entry into school, had they experienced authentic/facilitative inclusion for the 1-2 years they attended their early childhood centres. For children to experience facilitative inclusion requires early childhood centres ands schools to adopt a philosophy of difference, which embraces disability and other differences such as race and gender as valued attributes, as opposed to deficiencies or problems. Since transitions also had the potential to change children's 
Rietveld, C. (2004, November). Contextual Factors Affecting Inclusion during Children's Transitions from Preschool to School. CHILDforum $8^{\text {th }}$ Annual NZ Early Childhood Research Symposium, Wellington. Please cite author and reference if using this material.

favourable experiences of inclusion at preschool to exclusion at school (Neil), clearly more attention needs to be focused on the quality of educational inclusion for all children irrespective of impairment and type of educational setting.

That contexts influence facilitative inclusion more than children's individual impairments adds credence to the claims of disability theorists (Barnes, 2003; Clough \& Barton, 1995; Oliver, 1986, 1996), who argue that individual characteristics do not disable, but disability occurs as a consequence of participation in contexts which fail to cater for people with impairments. These results are also in agreement with previous research studies (Philips, 1997; Rietveld, 2004; Wolfberg, Zercher, Lieber, Capell, Matias, Hanson \& Odom, 1999) that have shown how children with intellectual impairments can be prevented from experiencing inclusion by preschool/school norms that do not accommodate children who move, behave and/or communicate in diverse ways.

The data also provide evidence for Bronfenbrenner's (1979) and Vygotsky's (1978; 1981) views that socio-cultural factors outside the classroom influence the quality of educational processes occurring in the classroom. Successful inclusion at the more distal levels of the mesosystem and exosystem involved: i) the presence of an existing school infrastructure which is capable of accommodating both the biological and socio-cultural diversity present in all key participants, ii) a vision of what successful inclusive outcomes might involve together with commensurate practices and iii) a model of disability focussing on the context which informs those practices.

While the institutional social context will affect the quality of inclusion in a significant way, the data suggest that taking into account the nature of the child's biological differences as they affect the teaching/learning process would also seem important. For instance, it will be recalled that Ian was able to participate actively in oral reading with his group as the teacher slowed down the pace of the group to enable such participation. Jonathan, on the other hand, was unlikely to be able to take part in the reading instruction with his group, as the reading pace of the group is likely to have been too fast, knowing differences in brain processing skills including encoding, storage and retrieval of information and speech movements associated with DS (Capone, 2004). He did not ever read aloud with the group in this context, despite 
Rietveld, C. (2004, November). Contextual Factors Affecting Inclusion during Children's Transitions from Preschool to School. CHILDforum $8^{\text {th }}$ Annual NZ Early Childhood Research Symposium, Wellington. Please cite author and reference if using this material.

observations indicating that he was able to read the books at home. While some users of the social model of disability downplay the impact of differing impairments on learning and living (Ballard, 1998; Education 267 Course Materials, 2003), this was never the intention of the social model's originators (Oliver, 1996; Barnes, 2003). Since the context is mediated by the within-child factors (Bronfenbrenner, 1979), which necessarily includes the child's impairment (biological diversity), this influence needs to be taken into account in any holistic view of children's development.

While this study has contributed to our understandings of what is involved in (facilitative) inclusion, it does not claim to have identified all the necessary components, linking mechanisms and practices. The small sample size involving one gender in one city and the use of observational methods which privileges the researcher's interpretation of events over children's call for a degree of caution in generalising from the data. At the same time, it is envisaged that others may be prompted by the data to study some of the issues in greater detail. It is only by further learning about the complexities of the processes children participate in and all the factors influencing those processes that it will be possible to create even more optimal and facilitative learning environments for all children.

\section{REFERENCES}

Appendices to the House of Representatives - Mental Health (1956). Appendix to the Journals of the House of Representatives of New Zealand, 1957, ()ㅡ, Wellington: New Zealand.

Bentley-Williams, R., \& Butterfield, N. (1996). Transition from early intervention to school: a family focussed view of the issues involved. Australasian Journal of Special Education, 20(2), 17-28.

Ballard, K. (1991). Integration through mainstreaming: towards inclusion. Paper presented to the New Zealand Spina Bifida National Conference, Auckland, New Zealand.

Ballard, K. (1998). Disability and Development. In A.B. Smith (Ed.), Understanding children's development ( $4^{\text {th }}$ ed.) (pp. 296-317). Welllington: Bridget Williams.

Barnes, C. (2003). What a difference a decade makes: Reflections on doing 'emancipatory' disability research. Disability \& Society, 18(1), 3-17. 
Bossert, S.T. (1979). Tasks and social relationships in classrooms. New York: Cambridge University Press.

Bronfenbrenner, U. (1979). The ecology of human development. Harvard: Harvard University Press.

Brown, C. (1994). Parents and professionals: future directions. In K. Ballard (Ed.), Disability, family, whanau and society (pp. 231-245). Palmerston North: Dunmore.

Capone, G.T. (2004). Down Syndrome: Genetic insights and thoughts on early intervention. Infants and Young Children, 17(1), 45-58.

Champion, P.R. (1987). An investigation of the sensorimotor development of down's syndrome infants. British Journal of Mental Subnormality, 33, Part 2, (65), 8899.

Clarke, A.D.B. \& Clarke, A.M. (1974). The changing concept of intelligence: a selective historical review. In Mental deficiency: The changing outlook $\left(3^{\text {rd }}\right.$ ed.). (pp. 143-163). New York: The Free Press.

Clough, P., \& Barton, L. (1995). Making difficulties: research and the construction of special educational needs. London: Paul Chapman.

Conn-Powers, M.C, Ross-Allen, J., \& Holburn, S. (1990). Transition of young children into the elementary education mainstream. Topics in Early Childhood Special Education, 9(4), 91-105.

Education 267 (2003). Inclusive education primary course information book. Christchurch, University of Canterbury.

Farber, B. (1960). Family organisation and crises: maintenance of integration in families with a severely retarded child. Monographs for the Society for Research in Child Development, 25(1), Serial No. 25.

Harlan-Simmons, J.E., Holtz, J., Todd, J., \& Mooney, M.F. (2001). Building social relationships through valued roles: three older adults and the community membership project. Mental Retardation, 39(3), 171-180.

Hunt, A. (2000). The lost years: from Levin mental deficiency colony to Kimberley centre. Anne Hunt: Nationwide Book Distributors Ltd, Christchurch.

Kliewer, C. (1998). Schooling children with down syndrome: toward an understanding of possibility. New York: Teachers' College Press.

MacArthur, J., Purdue, K. \& Ballard, K. (2003). Competent and confident children? Te Whariki and the inclusion of children with disabilities in early childhood education. In J. Nuttall (Ed.), Weaving Te Whariki (pp. 131-160). Wellington: NZCER. 
Miller, J.F., Leddy, M., Molo, G., \& Sedey, A. (1995). The development of early language skills in children with down syndrome. In L. Nadel \& D. Rosenthal (Eds.), Down syndrome: living and learning in the community (pp. 115-120). New York: Wiley-Liss.

Minister for Disability Issues. (2001). Making a world of difference: the New Zealand disability strategy. Wellington: Ministry of Health.

Neilson, W. (2000). Disability: Attitude, history and discourses. In D. Fraser, R. Moltzen \& K. Ryba (Eds.), Learners with special needs in Aotearoa New Zealand $\left(2^{\text {nd }}\right.$ edn.) (pp. 13-27). Palmerston North: Dunmore Press.

Oliver, M. (1986). Social policy and disability: some theoretical issues. Disability, Handicap and Society, 1(1), 5-17.

Oliver, M. (1996). Understanding disability; from theory to practice. New York: St Martin's Press.

Peters, S. (1997, November). Facilitating the transition to school: exploring the concerns of children, parents and teachers. Paper presented at the National Seminar on the Transition to school, Children's Issues Centre/Institute of Early Childhood Studies, Victoria University, Wellington, New Zealand.

Philips, R.J. (1997). Social interactions and social relationships between children with and without disabilities: shifting the focus. Unpublished MA Thesis, Education Department, University of Canterbury, New Zealand.

Renwick, M. (1984). To school at five: the transition from home or preschool to school. Wellington: New Zealand Council for Educational Research.

Rietveld, C.M. (2002). The Transition from Preschool to School for Children with Down Syndrome: A Challenge to Regular Education? (2002), Unpublished $\mathrm{PhD}$ thesis, University of Canterbury, Christchurch, New Zealand.

Rietveld, C.M. (2004, November). "I'm Participating. Is that Inclusion?" Classroom Learning experiences of Mathematics by new entrant children with Down Syndrome." Paper presented to NZARE conference, Westpac Stadium, Wellington, New Zealand.

Vygotsky, L.S. (1978). Mind in society: the development of higher mental processes. Cambridge, Mass., Harvard University Press.

Vygotsky, L.S. (1981). The genesis of higher mental functions. In J.V. Wertsch (Ed.), The concept of activity in Soviet Psychology. Armonk, New York: Sharpe.

Ward, J., \& Center, Y. (1988). The integration of children with intellectual disability into regular schools: results from a naturalistic study. In W.I. Fraser (Ed.), Key issues in mental retardation research (pp. 354-365). London: Routledge. 
Rietveld, C. (2004, November). Contextual Factors Affecting Inclusion during Children's Transitions from Preschool to School. CHILDforum $8^{\text {th }}$ Annual NZ Early Childhood Research Symposium, Wellington. Please cite author and reference if using this material.

Wartmann, S. (1997). Building blocks and barriers: the transition from kindergarten to school for children with special needs. Education Department, University of Canterbury, New Zealand. Research Report 97-1.

Wolfberg, P.J., Zerchar, C., Lieber, J., Capell, K., Matias, S., Hanson, M., \& Odom, S.L. (1999). "Can I play with you?” peer culture in inclusive preschool programs. Journal of the Association for Persons with Severe Handicaps, 24(2), 69-84. 